\title{
THE EFFECTIVENESS OF REMINISCENCE THERAPY IN IMPROVING ELDERLY'S WELL-BEING
}

\author{
Etty Sabariah Firdaus ${ }^{1}$; Nilam Widyarini² ${ }^{2}$ Martina Dwi Mustika ${ }^{3}$ \\ 1,2 Faculty of Psychology, Universitas Gunadarma \\ Jl. Margonda Raya No.100, Depok 16424, Indonesia \\ ${ }^{3}$ Faculty of Psychology, Universitas Indonesia \\ Jl. Lkr. Kampus Raya Jl. Mawar No.5 3 8, Depok 16424, Indonesia \\ 1'etty.sabariah@gmail.com; ${ }^{2}$ nilam@staff.gunadarma.ac.id; 3 martinadwimustika@gmail.com
}

Received: $14^{\text {th }}$ August 2019/ Revised: $26^{\text {th }}$ August 2019/ Accepted: 02 ${ }^{\text {nd }}$ September 2019

How to Cite: Firdaus, E. S., Widyarini, N., \& Mustika, M. D. (2019). The effectiveness of reminiscence therapy in improving elderly's well-being. Humaniora, 10(3), 191-196. https://doi.org/10.21512/humaniora.v10i3.5874

\begin{abstract}
The research discussed Subjective well-being (SWB) with reminiscence therapy in the elderly. This research used a single-case experiment design to examine the effectiveness of reminiscence therapy in improving the well-being of active, elderly aged 70 years old and over. There were two participants in this research, one male and one female. This intervention consisted of five meetings held once a week for \pm 90 minutes each session. Quantitative analysis using the Oxford Happiness Questionnaire and qualitative analysis through observation and interviews showed an improvement in participants'subjective well-being following the intervention. Therefore, the results of this research are likely that reminiscence therapy is effective in improving the subjective well-being of elderly individuals.
\end{abstract}

Keywords: Oxford Happiness Questionnaire, reminiscence therapy, subjective well-being, elderly therapy

\section{INTRODUCTION}

In the human life cycle that begins as an infant through to a toddler, teenager, adult, and finally old age, the old age is the period that attracts little attention. However, it is important for the other human life cycle periods. The Indonesian Central Bureau of Statistics stated that in $2050,25 \%$ of the Indonesian population would be elderly (Silviliyana et al., 2018). The World Health Organization classifies the elderly as those who are 60 years or older, and within this classification are the oldest-old who are 80 years or older, centenarians who are 100 years or older, and supercentenarians who are 110 years or older (World Health Organization, n.d.). Generally, 60 years of age is marked by deterioration in physical and psychological conditions.

The characteristics related to personal and social adjustment are changes in motoric ability, physical strength, psychological function, the nervous system, and appearance (Santrock, 2018). The developmental success of an elderly individual is influenced by the developmental success that individual achieves in the previous periods of their life (Monk, Knoers, \& Haditono, 2001; Santrock, 2018). These milestones include the development of cognitive or intellectual skills, the understanding of and ability to control emotions, choosing and preparing for a career, planning and starting a family, achieving socially responsible behavior, understanding the ethical value of the community in interpersonal patterns, and understanding and practicing the values of faith and piety according to individual beliefs (Monk, Knoers, \& Haditono, 2001; Santrock, 2018). If successful in reaching these milestones, happiness will follow. However, the opposite will occur if there is a failure - the individual will be disappointed or will face difficulties or obstacles into old age (Santrock, 2018).

The development of human life involves cognitive ability (i.e., memory, creativity, and intelligence), and learning ability that includes physical impairment. Generally, learning processes, memory, and intelligence decrease concurrently with age, as does the speed in which new information is processed and the ability with which information stored in memory is re-released (Santrock, 2018). However, the information processing speed is also influenced by the individual. The aging process is not only concerned with adjustments to age-related loss or decline but also the development of new capacities and the search for new challenges. Recognizing the personality characteristics and the developmental tasks of the elderly can help this age group through the process of getting old in the right way to achieve a quality of life that ensures they are happy.

Happiness is an individual state that is meaningful in 
a positive sense (Zajenkowski, 2018). To achieve happiness, an individual must be able to identify, process, train, and use their strengths and virtues to respond to various situations or challenges in everyday life. Following two weeks of field observations in the Panti Tresna Werda Ministry of Social Affairs located in Bulak Kapal Bekasi between March 2 and March 15,2012, it was found many of the elderly participants who had not achieved happiness psychologically tended to complain often due to feelings of loneliness, excessive fear, being rejected, not being useful, and due to poor abilities in controlling emotions, often causing unnecessary conflict.

Results from the observations of researchers at Baitul Hasan Mosque, Lenteng Agung, and Baitul Fattah Mosque, Cilandak, show that several of the elderly, although pious and frequently attended the mosque, tend to be less happy, often complained, and feel upset, regretful, and irritable. Conversely, there is a group of elderly who show that they are satisfied and happy with all their achievements in life. They enjoy life, do various activities that benefit others, enjoy their time and relationship with their family and social surroundings, and many other positive things. The specific groups of elderly who display these characteristics have a characteristic that is referred to as 'subjective well-being' (SWB) (Diener, Oishi, \& Lucas, 2003; Schimmack et al., 2002; Woyciekoski, Natividade, \& Hutz, 2014).

The researchers mainly use the SWB theory and reminiscence therapy approach in this research. SWB refers to how people evaluate their life (Diener, Oishi, \& Lucas, 2003). SWB can be assessed using the SWB scale that assesses pleasant emotion, unpleasant emotion, global life satisfaction, and satisfaction aspects (Diener, Oishi, \& Lucas, 2003; Schimmack et al., 2002). It also includes variables, such as satisfaction in life and marriage, the absence of depression and anxiety, and the existence of positive mood and emotion. SWB broadly categorizes the phenomenon of an individual's emotional response, satisfaction domains, and global assessments of life satisfaction (Diener, Oishi, \& LUcas, 2003; Schimmack et al., 2002). Further, the SWB score of an individual is observed from the main variables of happiness and life satisfaction (Jarden, 2012; Grant, 2001). Thus, the elderly with a high SWB score are satisfied with life, often feel happy, and seldom feel unpleasant emotions, such as upset or angry. Conversely, the elderly with a low SWB score are less satisfied with life, rarely feel happy, and more often feel unpleasant emotions, such as anger or anxiety.

An individual is said to have a high SWB if they rarely experience negative emotions (Diener, Oishi, \& Lucas, 2003; Zajenkowski, 2018). A high negative affective state is a state in which a person feels anger, hatred, guilt, fear, and anxiety, whereas, in a low negative affective state, a person feels serenity and peace (Tellegen, Watson, \& Clark, 1988; Wang et al., 2014). An individual with emotional or affective responses, either experienced as mood or emotion, tends to represent information directly and evaluate relevant events in their environment (Diener, Oishi, \& Lucas, 2003). Although some negative emotions are expected to occur in life and are needed for one to live effectively, frequent and prolonged negative emotions indicate that an individual believes that their life is progressing unsatisfactorily (Diener, Oishi, \& Lucas, 2003; Kadota \& Terasaki, 2009). Further, prolonged negative emotions can disrupt how an individual behaves effectively in their everyday life, causing their lives to become unpleasant.

Achievement of SWB in the elderly is based on a series of journeys or life events that diverge from those who have not reached sufficient SWB. Therefore, it is important to understand the journey of those who have attained SWB, such as how they respond or react to facing retirement, their marriage status, or how they establish more meaningful social relations outside work. After obtaining an overview of the conditions of SWB, these data will be processed and analyzed to generate a how-to guide in achieving the conditions of SWB that can be used by the elderly to achieve the same conditions.

A reminiscence therapy approach is mainly used to obtain a record of the life activities of elderly participants with good SWB and to attempt to increase SWB scores. Reminiscence therapy is remembering the past by reflecting on the experience or events in their life and retelling the story of their life. It may provide a therapeutic effect when it is used as a structured intervention involving guidance for the elderly client (Butler, 1963; Hyams \& Scogin, 2015). Therapy using reminiscence is a treatment intervention that may be very helpful in maintaining or improving self-esteem and life satisfaction for the elderly (Butler, 1963). Further research is required to understand reminiscence therapy's use, especially empirical research, to evaluate the use and effectiveness of reminiscence in the elderly. However, reminiscence therapy as an intervention technique is challenging because of the scarcity of research into this field, the measurement methods that are dependent on each other, different data collection methods, different population sets, and small sample sizes (Butler, 1963). Thus, a reformulation of concepts and standards around reminiscence measurement methods and guidelines is required.

In the context of this research, reminiscence therapy serves to uncover the various events of an elderly individual's life journey that leads them to the condition of SWB. This therapy process will automatically increase the self-esteem of participants since discussing the past will direct them to appreciate their progress and achievements. By using the results of this analysis of participants with $\mathrm{SWB}$, the researchers argue that reminiscence therapy may also be provided to the elderly who have not reached SWB through counseling or intervention in an effort to improve their SWB.

\section{METHODS}

Single-Case experiment design is used in this research. An A-B-A design is used that shows a causal relationship between dependent and independent variables. Behavioral targets are measured continuously at baseline conditions (A1) for a certain period of time under intervention conditions (B), then the measurement is repeated at the second baseline condition (A2). The addition of the second baseline condition (A2) is intended as a control for the intervention phase. Thus, it is possible to draw an early conclusion about the functional relationship between the independent and dependent variables prior to the intervention. In phase $\mathrm{B}$, researchers provide for participants an intervention or treatment spanning approximately three meetings. In the second phase $\mathrm{A}$, researchers perform baseline measurements after the intervention has been provided to study participants (Aldridge, 2018; Kazdin, 2015).

The research participants are two elderly people; one male and one female, aged over 70 years. Both participants are active in religious and routine activities and 
are willing to participate in this intervention. Participants are selected based on the condition that each has the right and opportunity to improve their quality of life. While the participants already have good SWB, there remain many opportunities to improve SWB in these elderly participants, one of which is through reminiscence therapy. Therefore, it is expected that after undergoing this intervention, the participants could reach their optimum SWB and be able to provide peer support to others to reach an improved SWB.

This research measures the effectiveness of an intervention based on the pre-post-test assessment of a questionnaire, daily journal, observation, and interview. During the pre- and post-intervention, an Oxford Happiness Questionnaire (OHQ) (Hills \& Argyle, 2002) is used to understand the SWB of participants. The OHQ consists of 29 statements using a six-point scale ranging from strongly disagree to strongly agree.

In each intervention session, the researchers also collect data using behavioral observations of participants, enabling the researcher to analyze changes in the development, and the difficulty experienced by the participants in each session. The observation guideline contains the characteristics of behavior that the researchers want to observe relating to the research objectives. This guideline is used during the research process, but if there are aspects that are not contained in the observation guideline but related to the research problem, it is also included to enrich the results of the research. The recording of observations is performed by the written record.

A guided interview method is undertaken, whereby the interviewer only follows a general interview guideline relating to the research problem with no specific set or order of questions. The researchers develop a series of questions about participant SWB that related to the research questions, do not deviate from the research objectives, and allow for sufficient inquiry of SWB in the elderly. Subsequently, the interview process follows the situation and condition of participants already in old age and is expected to explore the in-depth information required to provide reminiscence therapy.

Informed consent is obtained prior to data collection and intervention. The researchers then perform a needs analysis through interviews of potential participants. Rapport is developed prior to the intervention to improve the trust and comfort between participants and researchers during the data collection and intervention process. The findings from the needs analysis show that participant 1 has experienced distress in the form of anxiety due to thinking about the conflict that occurs in her child's household. Participant 2 is also concerned, but about the working conditions and employment status of one of his children, whose employer is experiencing a decrease in orders. The researchers intend to improve the life review of the elderly participants by using their past experience as a basis to improve problem-solving skills, find the balance between past and present experiences, and gain insight into how participants improve throughout their life cycle to the present. The research is conducted to improve SWB in participants through structured reminiscence therapy and life review of participants. Upon agreement with participants, the researchers conduct an initial interview to understand their SWB. The intervention process is performed using a theoretical guideline that outlines the stages of structured reminiscence therapy and life review.

The research implementation phase is planned for over five weeks and consisted of a pre-test, intervention, and post-test. The intervention comprises five weekly meetings for each participant with a duration of between 60 and 90 minutes, depending on participant comfort. The intervention takes place each Saturday for participant 1, and each Sunday for participant 2. However, any changes to the agreed day and time are adjusted to maintain rapport with the elderly participants. The first researcher becomes the counselor in this research under supervision by the second researcher.

Structured reminiscence therapy and life review are divided into five sessions. Nurturing rapport is always maintained to ensure a positive relationship between participants and the counselor. The counselor also provides relaxation and checked in on participants' feelings at the beginning and end of each session to improve participants' comfort during the intervention and to understand the conditions of their SWB. In the first session, the counselor explains the purpose and objectives of the intervention. This is followed by relaxation, the provision of the first pre-test questionnaires, and a reflection of the past session. Remembering the previous session is provided to explore the meaning of life and creating more value for participants' past experiences. The second session focuses on understanding participants' life issues relating to their minds, emotions, sensations, memories, and strategies used to solve those issues. In the third session, the discussion is focused on how participants solve their problems to discover the continuity between their past and present life events. In the fourth session, the discussion is centered around helping participants discover insight into the problem-solving strategies that they use to reach their current life condition, such as their habits and achievements. In the final session, the counselor and participants review all previous sessions and discussed the benefits of the intervention to help participants reach their SWB and problem-solving skills. The intervention is appropriately finalized, and feedback sought from participants.

The intervention's indicator of success is achieved by investigating improvements or changes to participants' perceptions of their SWB. The changes are determined through score differences in the OHQ that are completed by participants during the pre- and post-intervention. The results are supported by the qualitative evaluations undertaken in the interviews, and in the observations in which each participant reveals any changes feel the following intervention. Participants also reveal the extent to which their initial expectations are achieved at the end of the therapy sessions. Thus, the research records the benefits of the overall intervention program and its effectiveness in assisting participants to improve their SWB.

Quantitative data analysis in this research is conducted by comparing the result of the pre- and post-tests from the OHQ scale using the A-B-A design. In addition, the researchers also perform qualitative analysis in the form of observations and interviews to achieve sufficient data to determine SWB in the elderly participants.

\section{RESULTS AND DISCUSSIONS}

The results from the interviews show that participants 1 and 2 already have several characteristics of SWB. They have routine activities, good social relationships, and are active in religious activities. However, the current condition of the research participants includes distress, in which participant 1 feels distressed over thinking about one of 
her children's marital conflicts while participant 2 feels distressed over thinking about the current employment status of one of his children that could lead to employment termination. The following are the results for each participant.

"I always deal with my grand daughters as I dealt with my children, so they would not be spoilt. So, when time to play, I took them to play basketball, table tennis or even singing. Whatever I cook, they always eat. Just look how healthy they are!" (Participant 1)

The participant is the eldest of the 11 siblings. After graduating from the faculty of dentistry, she had taught at a university level for 15 years. At 60 years old, she learns acupuncture and remains active in practicing this form of medicine on an appointment basis. According to Participant 1 , although she feels happy due to several achievements, she often feels worried thinking about the future of one of her children that currently is having marital concerns. The result of OHQ suggested that Participant 1 is very happy $(\mathrm{OHQ}$ score $=5,10)$, feeling happy about the positive values in other people and that life is promising, feeling warm toward other people, and feeling content with everything she wants. Participant 1 does not agree with several items of the questionnaires (each OHQ score $=2$ ) in that she feels she lacks sleep and is pessimistic about the future.

From the observation and interview, it can be concluded that Participant 1 is generally satisfied with her life. She is grateful that she has completed her duties and obligation as a wife and mother for her children and as a civil servant, as she has said:

"I am grateful that although I did not give a lot of worldly material, but Thank God they all could finish their studies. Thank God I was able to look after my husband during his illness up to his passing. Often, in my prayer, I always cry when remember about attention and kindness of my husband. It is ok to cry right? I am rather whiny, I guess?" (Participant 1)

Participant 1 shows a happy expression when telling about her past experiences and feeling grateful and happy about being able to provide a good education for her children. She has many happy memories with her husband. She also has a positive potential and positive values. However, Participant 1 feels worried and confused thinking about one of her children who is having marital conflict. She is upset over this marital conflict as if her existence does not offer a meaningful contribution in trying to resolve the situation.

From the results of the needs assessment, Participant 2 currently feels happy and healthy. He attempts some sports or physical activities to maintain his healthy condition by regularly consuming a homemade herbal drink. He also realizes that each individual should have an awareness to face any changes when becoming old. Before he retired, Participant 2 worries that he would lose contact with his friends. However, thanks to technological advancement, he still maintains contact with his friends through the mailing lists WhatsApp, text messages, and e-mail. He is worried about his child's employment status that may lead to termination.

In general, his current condition of SWB is very happy (OHQ score $=5,034$ ). He feels life is promising, warm toward all people, and many other pleasant things. He describes that he is often involved in an activity and is responsible for that role, feels that life is beautiful, pleasant, cheerful, and feels content with his life. However, unfavorable results for some statements in the questionnaire (OHQ score $=2$ ) indicates that he feels doubtful about his ability, less optimistic about his future, and what he does is different from what he wants.

The observation and interview have suggested that Participant 2 has life satisfaction and is grateful, happy, and content with his life. Participant 2 feels he could benefit other people during his active working life up to the present. Participant 2 indicates that he is often requested to provide advice or assist in resolving internal conflict within the company. His expression is also happy when telling about his past experiences and events that occurred in the past and during his lifetime. Participant 2 feels happy with his accomplishments, successful in his career, and proud that his children are able to complete their education. However, he feels anxious about the work of one of his children. At the time of the interview, the company that his child works for is experiencing a decrease in turnover due to the weakening rupiah against the United States dollar. Participant 2 is worried that his son's employment would be terminated.

The reminiscence therapy intervention in the elderly is arranged based on stages and as an indicator of improved SWB. Participants also fill out the pre-post-test questionnaire as an overview of the improved conditions of the SWB. The first stage of the intervention begins with the provision of relaxation for participants to gain skills in developing the ability to overcome anxiety or tension they might face. In addition, it is intended that the provision of relaxation would enable participants to accept the intervention process easily. The second and third stages involve aspects of cognition and affection, a process of remembering the past and happiness from the past, gaining meaning and insight from past thinking to enhance current problem-solving and decision-making abilities. By providing the intervention in two stages, it reduces the difficulty and increases the ability to attain a positive view, leading participants on a path of improved spiritual condition. The fourth stage relates to the pattern of reminiscence that is owned by participants. The fifth stage includes the process of communication and observing the process of communication conducted by participants in facing each problem and how they communicated in the family environment or surroundings. The last stage is the evaluation stage, and the interventions in this stage are performed based on pre-post-test results that are filled out by the participants.

The findings from the intervention show that both participants change, both quantitatively and qualitatively, in an effort to improve the SWB. Quantitatively, Participant 1 's OHQ scores increase from a pre-test OHQ result of 5,10 (i.e., very happy) to a post-test OHQ result of 5,83 (i.e., very happy to almost too happy $[\mathrm{OHQ}=6])$. In other words, the participant is almost very happy looking back at her life. Qualitatively, the results from the observations and interviews show that Participant 1 is happy and aware (i.e., gained insight) of agreed imposed limitations by her late husband not to engage in their children's domestic conflict. She feels helped by remembering some of the past events that had been forgotten. In recalling, Participant 1 realizes she was still able, and her worry and anxiety diminished. She accepts that her child's household is young, but will still pray and encourage her child and partner to visit a marriage counselor. However, Participant 1 realizes that in the case of 
her child's divorce, she will accept it as the destiny of God. Quantitatively, Participant 2's OHQ score improves from a pre-test OHQ score of 5,034 (i.e., very happy in terms of SWB) to a post-test OHQ score of 5,86 (i.e., very happy to almost too happy $[\mathrm{OHQ}=6])$. Thus, Participant 2 is almost very happy looking back at his life. Qualitatively, results from the interview and observation of Participant 2 show an improvement in SWB relating to decreasing negative effects aspect. Following the intervention, Participant 2 realizes that the problem being faced by his child who is afraid of losing his employment is common (i.e., gained insight). Participant 2 has never experienced these things. This increasingly awakens the participant to understand that his child should try to find alternative work if his employment is terminated, and even if it happens, by asking God for help, God will replace his child's career with a better one.

Participants 1 and 2 are exposed to an intervention that accords with the statement that SWB is a positive experience, which is the core concept of positive psychology, and a pleasant and positive experience that can make life more valuable (Diener, Oishi, \& Lucas, 2003). They have a high level of SWB if they often feel positive emotions. Positive affection is a fun event experienced by a person in their life and refers to the extent to which the individual experiences a positive emotional state. In addition, the existence of life satisfaction experienced will affect how an individual improves the positive affect and reduces the negative effect in the event experienced (Diener, Oishi, \& Lucas, 2003).

This research contributes to add more evidence of the effectiveness of reminiscence therapy in improving the elderly's subjective well being. The results of the intervention indicate that reminiscence therapy is effective in reducing distress in both participants. This effectiveness can be observed through the insight obtained by the participants when recalling or referring to past experiences and how this insight is used to address problems that are encountered in the present. Reminiscence therapy can be effectively applied to the elderly because by referring to their individual life experiences, it provides control to the elderly in how they respond to current problems, and is not based on advice or input from the counselor. In addition, reminiscence therapy can be effective in increasing the selfesteem of the elderly to achieve optimal conditions of SWB by stimulating them to remember their past successes or achievements.

Defining the period of old age tends to be difficult, although some sources indicate that 65 years and above is considered old age (World Health Organization, n.d.). The latest developmental task of an individual is influenced by the success or failure of their development in the previous period. Many people assume that in old age, the development of individuals is stopped, and they are just waiting for death (Santrock, 2018). However, an elderly individual must also undergo a separate developmental task that must be achieved to sufficient welfare until death. This elderly developmental task will be achieved when past developmental tasks develop accordingly. Thus, an elderly individual can adjust and respond appropriately to the various changes that occur in the present to achieve happiness or SWB (Santrock, 2018).

Based on the results of this intervention, it is implied that reminiscence therapy is effective in relieving distress in participants when facing their current problems. Further, the conditions of participants' SWB can increase even if each participant has sufficient SWB. This therapy is also considered appropriate for the elderly because it focuses on exploring individuals' past experiences or successes to respond to problems in the present. Focusing on the past like this will allow the elderly to still feel in control over themselves and will increase their self-worth by remembering their past successes or achievements. It is important to consider how the elderly can continue to be productive and can achieve optimal SWB as one of the fulfillments of human rights, namely the opportunity to grow and develop (Diener, Oishi, \& Lucas, 2003). However, currently, the welfare of the elderly is not a priority, so providing support to this age group will encounter many challenges. Therefore, a peer-support approach and further research are required, such as training of suitable elderly individuals in reminiscence therapy techniques so they can help other elderly individuals to achieve the conditions of SWB.

For the researchers, this research can be used as a foundation and reference for subsequent studies related to improving SWB in the elderly through reminiscence therapy. The indicators used in this research can be used independently of, related to, or connected with other indicators outside this initial research. Additional research could be conducted on elderly participants with different criteria, such as individuals with low SWB, to determine how reminiscence therapy can assist these individuals in reaching an improved SWB.

\section{CONCLUSIONS}

Reminiscence therapy is one way to meaningfully increase life expectancy because it provides to the elderly control in how they respond to current problems with reference to their subjective life experiences. To achieve optimal SWB conditions, the elderly can be stimulated to remember their past achievements.

One limitation that the researchers noticed is that participants in this research may not be completely appropriate to receive therapy since they are most likely a healthy elderly. Therefore, based on the results of this research, the following recommendations are provided. Participants who have undertaken reminiscence therapy by telling stories about the past (i.e., for Participant 1, this process makes her feel happy) gain experience in a process that is easy and can be repeated individually or in groups. By doing this therapy routinely, the elderly can be expected to maintain the conditions of their SWB.

Further research is needed, including providing training of reminiscence therapy techniques and peer support to elderly groups. Further research needs to be conducted specifically in the form of drafting guidance on reminiscence therapy approaches that are suitable to elderly groups and the conditions and situations they face in Indonesia. It is expected that this guideline can be used as a basic program in elderly treatment centers.

\section{REFERENCES}

Aldridge, D. (2018). Single-case research designs for the clinician. Journal of the Royal Society of Medicine, 84(5), 249-252. https://doi. org/10.1177/014107689108400502. 
Butler, R. N. (1963). The life review: An interpretation of reminiscence in the aged. Psychiatry, 26, 65-76. https://doi.org/doi.org/10.1080/00332747.1963.110 23339.

Diener, E., Oishi, S., \& Lucas, R. E. (2003). Personality, culture, and subjective well-being: Emotional and cognitive evaluations of life. Annual Review of Psychology, 54, 403-425. https://doi.org/10.1146/ annurev.psych.54.101601.145056.

Grant, R. J. (2001). Positive psychology: An introduction. Journal of Humanistic Psychology, 41(1), 8-13.

Hills, P., \& Argyle, M. (2002). The Oxford happiness questionnaire: A compact scale for the measurement of psychological well-being. Personality and Individual Differences, 33(7), 1073-1082. https:// doi.org/10.1016/S0191-8869(01)00213-6.

Hyams, A., \& Scogin, F. (2015). Reminiscence/life review therapy. In The Encyclopedia of Clinical Psychology (pp. 1-3). https://doi.org/10.1002/9781118625392. wbecp148.

Jarden, A. (2012). Positive psychologists on positive psychology: Introduction. International Journal of Wellbeing, 2(2), 70-71. https://doi.org/10.5502/ijw. v2i2.1.

Kadota, M., \& Terasaki, M. (2009). Personality, daily life events, and subjective well-being. The Japanese Journal of Personality, 18(1), 35-45. https://doi. org/10.2132/personality. 18.35 .

Kazdin, A. E. (2015). Single-case experimental research designs. In Methodological issues and strategies in clinical research ( $4^{\text {th }} \mathrm{Ed}$.). (pp. 459-483). https://doi. org/10.1037/14805-029.

Monk, E. J., Knoers, A. M. P., \& Haditono, S. R. (2001). Psikologi perkembangan: Pengantar dalam berbagai bagiannya. Yogyakarta: Gadjah Mada University Press.

Santrock, J. W. (2018). A topical approach to life-span development ( $8^{\text {th }}$ Ed.). New York: Mc Graw Hill.
Schimmack, U., Oishi, S., Radhakrishnan, P., Dzokoto, V., \& Ahadi, S. (2002). Culture, personality, and subjective well-being: Integrating process models of life satisfaction. Journal of Personality and Social Psychology, 82(4), 582-593. https://doi. org/10.1037/0022-3514.82.4.582.

Silviliyana, M., Maylasari, I., Agustina, R., Ramadani, K. D., Sulistyowati, R., Annisa, L., \& Dewi, F. W. R. (2018). Statistikpenduduklanjut usia 2018. Retrieved from https://www.bps.go.id/publication/2018/12/21/ eadbab6507c06294b74adf71/statistik-penduduklanjut-usia-2018.

Tellegen, A., Watson, D., \& Clark, L. A. (1988). Development and validation of brief measures of positive and negative affect: The PANAS scales. Journal of Personality and Social Psychology, 54(6), 1063-1070. Retrieved from http://www.ncbi. nlm.nih.gov/pubmed/3397865.

Wang, L. L., Shi, Z. B., Zhang, J. F., \& He, L. (2014). Couples' subjective well-being and personality. Chinese Mental Health Journal, 28(9), 690-694. Retrieved from http://search.ebscohost.com/login. aspx ?direct $=$ true $\& d b=$ psyh $\& A N=2014-44072$ $010 \&$ site $=$ ehost-live $\&$ scope $=$ site.

World Health Organization. (n.d.). Health situation and trend assessment: Elderly population. Retrieved June 25 2019 from http://www.searo.who.int/ entity/health_situation_trends/data/chi/elderlypopulation/en/

Woyciekoski, C., Natividade, J. C., \& Hutz, C. S. (2014). Contributions of personality and life events to the subjective well-being. Psicologia: Teoria $e$ Pesquisa, 30(4), 401-409. https://doi.org/10.1590/ S0102-37722014000400005.

Zajenkowski, M. (2018). Personality and subjective wellbeing. In Encyclopedia of Personality and Individual Differences (pp. 1-5). https://doi.org/10.1007/9783-319-28099-8_2116-1. 